\title{
Assessment of Urea and Creatinine in Vaginal Washing Fluid as a Method for Diagnosis of Premature Rupture of Membranes
}

\author{
SAFAA ABDEL-SALAM IBRAHIM, M.D. and AHMED MAHMOUD FARAG, M.D. \\ The Department of Obstetrics and Gynecology, Faculty of Medicine, Zagazig University, Egypt
}

\begin{abstract}
Background: Premature rupture of membranes (PROM) refers to rupture of fetal membranes prior the onset of labor. If it occurs before 37 weeks of pregnancy, it is known as preterm premature rupture of membrane (PPROM). Prolonged duration from PROM till delivery is associated with increased maternal and neonatal morbidities, in term and preterm pregnancies. This includes chorioamnionitis, fetal and neonatal sepsis, placental abruption, prematurity, umbilical cord prolapse, and increased rate of cesarean delivery.
\end{abstract}

Pregnant women with history of vaginal leaking or ultrasound evidence of diminished amniotic fluid should be carefully evaluated to avoid adverse pregnancy outcomes. Accurate diagnosis helps obstetricians to optimize maternal and neonatal outcomes by early intervention to decrease morbidities.

Diagnosis of PROM is may be easy by inspection of leaking through the cervix or fluid accumulation via speculum examination. However, with small rupture of membrane or rupture bag of hind-water, it is difficult to see amniotic fluid leakage clearly and diagnosis can't be easily made, which might lead to delay in diagnosis and management.

Methods of PPROM diagnosis include fern and nitrazine which are two commonly used and traditional tests. They are rapid and easy tests but not completely reliable because of high false positive and negative results, which may be related to technical errors or contamination by blood, semen or cervical mucus.

Ultrasound evaluation of amniotic fluid can't differentiate PROM from other causes of oligohydramnios. However, tampon or amnio-dye test is a test of accurate diagnosis through aspiration and dye injection into amniotic fluid under ultrasound guidance. It is an aggressive test with has a risk of bleeding, placental abruption infection, miscarriage, and iatrogenic uterine perforation.

The Amnisure test for ROM is accurate but expensive and not available in many centers. Thus, a simple, noninvasive, and inexpensive method of detecting PROM is needed. Urea and creatinine are excreted by kidneys through glomerular filtration. Amniotic fluid also contains these markers and their determination in the vaginal can be used as a diagnostic test for PROM.

Correspondence to: Dr. Ahmed Mahmoud Farag, The Department of Obstetrics and Gynecology, Faculty of Medicine, Zagazig University, Egypt
Aim of Study: This study was conducted to evaluate the diagnostic value of urea and creatinine levels in vaginal wash in patients with suspected PROM.

Patients and Method: The study was carried out at $\mathrm{Ob}$ stetrics and Gynecology Department, Zagazig University Hospitals. A total of 228 pregnant women were included in study, between completed 24 weeks to completed 37 weeks' gestation. Divided into two equal groups: Group A with definite PROM, control Group is B. All pregnant women included in this study were subjected to: Full history taking, general, abdominal and speculum examination, fern test and nitrazine test. Vaginal wash urea measurement by enzymatic urease examination method and vaginal wash creatinine measurement by RATE JAFFE method.

Results: The study showed that there is statistically significant difference between the two groups regarding vaginal wash urea and creatinine. The best cut-off value of vaginal wash urea in prediction of PROM is $>16.85 \mathrm{mg} / \mathrm{dl}$ with AUC of 0.958 , sensitivity of $98.2 \%$, specificity of $70.2 \%$, PPV of $76.7 \%$, NPV of $97.6 \%$ and accuracy of $93 \%$. The best cut-off value of vaginal wash creatinine in prediction of PROM is $>! 0.465 \mathrm{mg} / \mathrm{dl}$ with AUC of 0.992 , sensitivity of $100 \%$, specificity of $80.7 \%$, PPV of $83.8 \%$, NPV of $100 \%$ and accuracy of $90.4 \%$. Combined use of vaginal wash urea and creatinine in prediction of PROM had sensitivity of $98.3 \%$, specificity of $91.2 \%$, PPV of $91.8 \%$, NPV of $98.1 \%$ and accuracy of $94.7 \%$.

Conclusion: This study concluded that urea and creatinine assay in vaginal fluid is cheaper, faster and more valid test, possible candidate for being a gold standard test for diagnosis of PROM.

Key Words: Urea-Creatinine - Premature Rupture of Membranes (PROM).

\section{Introduction}

PREMATURE rupture of membrane (PROM) is a break in the amniotic sac prior the onset of labor after 37 weeks' gestation. Pregnant women usually claim a gush or a steady fluid leaking per vagina. If it's developed before 37 weeks' gestation, it is called PPROM (preterm premature rupture of membrane) [1]. PROM diagnosis is difficult with slow leaking, associated vaginal bleeding, or if there is no history of gush of fluid. 
Risk factors include infection of the amniotic fluid, weak membranes, antepartum hemorrhage, genetic, smoking, and underweight mothers. Fetal complications may include prematurity, cord compression or infection. Maternal complications may include chorioamnionitis, placental abruption or postpartum endometritis [2].

Ultrasound evaluation of amniotic fluid can't differentiate PROM from other oligohydramnios causes. The Amnisure test is a new test for detection of PROM. It's minimally invasive, fast, and easy with high specificity and sensitivity. However, Amnisure it is expensive and not available in many centers [3].

Hence, a simple, inexpensive, and non-invasive method of detecting PROM is needed. Several markers have been studied such as fetal fibronectin, a-fetoprotein, insulin growth factor binding protein 1 , urea, creatinine, 0 -hCG, and prolactin. Urea and creatinine are excreted by the kidneys through glomerular filtration, and also available within the amniotic fluid and have been used for PROM testing [4].

Kariman et al. [5] studied vaginal wash fluid for urea and creatinine levels. 84 pregnant women in two equal groups, one with confirmed PROM and the other include controls. The mean level of urea and creatinine in vaginal fluid in the PROM group was significantly higher than in intact fetal membranes group. They considered that measuring urea and creatinine of cervico-vaginal wash fluid confirms PROM diagnosis in the absence of blood and urine contamination.

\section{Patients and Methods}

This cross-sectional study was carried out at the Department of Obstetrics and Gynecology, Zagazig University Hospitals in the period from April 2018 to April 2019. It was based on clinical and biochemical parameters. It included 228 pregnant with gestational age from completed 24 weeks' gestation onwards.

Ethical Committee of Zagazig University Hospitals approved the study and informed written consent was taken from all patients.

Patients were divided into 2 equal groups as follows:

Group A (definite ROM):

It comprised 114 pregnant women with PROM with the following inclusion criteria:

1- Gestational age from completed 24 weeks to completed 37 weeks.
2- Singleton pregnancy.

3- History of watery vaginal discharge.

4- Positive fluid leaking by sterile Cusco speculum examination.

Group B (control group):

It comprised 114 pregnant women who were attending the outpatient clinic for routine antenatal care with the following inclusion criteria:

1- Gestational age from completed 24 weeks to completed 37 weeks.

2- Singleton pregnancy.

3- No history of vaginal fluid leaking.

4- Average amount of liquor.

Exclusion criteria:

- Blood seen in the vaginal secretion.

- Meconium stained liquor.

- History of coitus in the previous night.

- Using vaginal drugs.

- Sonographic evidence of IUFD or fetal malformation.

- Patients in labor.

Methods: All recruited pregnant women were subjected to:

Full history taking:

Personal history, LMP, history of fluid leaking (amount, onset, duration and fluid color), obstetric history and past history of fluid leaking or vaginal bleeding in previous pregnancies.

\section{General examination:}

Vital signs (pulse, temperature, blood pressure and respiratory rate), jaundice, pallor, cyanosis, edema (generalized or localized), heart and chest examination.

\section{Abdominal examination:}

Including fetal heart sound, fundal level, uterine contraction, abdominal tenderness and rigidity.

Results of speculum examination, fern test and nitrazine test:

1-Pooling test: Inspection of amniotic fluid pooling in the vagina.

2- Nitrazine test: Nitrazine is a $\mathrm{pH}$ indicator dye often used in medicine. Fluid collected from the vagina by a sterile cotton swab is placed on nitrazine paper. Normal vaginal secretions are acidic ( $\mathrm{pH} 4.5-6)$, while amniotic fluid is alkaline $(\mathrm{pH}$ 7.1-7.3) and will turn the nitrazine paper from orange to blue. A blue strip means it's most likely the membranes have ruptured. 
3- Ferning test: Fluid collected from the vagina by a sterile cotton swab is placed on a slide and examined by microscope. Amniotic fluid is left to dry and seen under a microscope, it will form crystals resembling fern plant leaves called arborization.

Patients with confirmed pooling, positive nitrazine paper test and positive fern test were categorized as (Group A). On the other hand, patients with negative results for these tests were taken as (Group B).

\section{Transabdominal ultrasonography:}

For assessment of fetal viability, Gestational age, placental site, fetal anomalies and amniotic fluid index. Gestational age was determined based on reliable first day of LMP, or one ultrasound in before 24 weeks or two ultrasound documents between 24 and 37-weeks' gestation.

Vaginal wash urea measurement by enzymatic urease method:

Urea Agar is used for the differentiation of enteric bacilli. The urease test is used to determine the organism ability to split urea, through the production of urease enzyme.

\section{Interpretation of urease test:}

Positive Reaction: Change to bright pink color, usually complete after $3-5$ hours at $35^{\circ} \mathrm{C}$.

\section{Negative Reaction: No color change.}

Vaginal wash creatinine measurement test by Jaffe reaction:

The Jaffe reaction is a colorimetrical test used to determine the level of creatinine in urine and blood. Creatinine from the sample combines with the reagent to quantitatively produce an orange color with picric acid in alkaline medium. Color is developed after incubation at room temperature for $15 \mathrm{~min}$ and measured at $520 \mathrm{~nm}$. The change in color is directly prorated with creatinine concentration. The Jaffe reaction, in spite of being old nonspecific test for creatinine, but still greatly appointed as the method of choice for creatinine testing because of its speed, flexibility in automated analysis, and cost-effectivity.

\section{Statistical analysis:}

Data were processed, verified and analyzed using Epi-info version 6 and SPP for Windows (6). Data were summed up using mean, Standard Deviation (SD) Sensitivity, Specificity, Accuracy and Predictive values.
The magnitude of significance is belayed at $5 \%$ level ( $p$-value).

The outcome is deemed:

- Significant when the error prospect is $<5 \%$ $(p<0.05)$.

- Non-significant when the error prospect is $>5 \%$ $(p>0.05)$.

- Highly significant when the error prospect is $<0.1 \%(p<0.001)$.

- Higher significance is related to smaller $p$-values.

\section{Results}

This cross-sectional study was executed at the Obstetrics and Gynecology Department, Zagazig University Hospitals in the period from April 2018 to April 2019. It was based on clinical and biochemical parameters. It was performed on 228 pregnant women with gestational age from completed 24 weeks onwards They divided into: Group A (definite rupture of membranes) included 114 pregnant women with history of ROM and Group B (control group) included 114 pregnant women attending the outpatient clinic for routine antenatal care.

Table (1) found no significant difference between both groups regarding age and BMI. In Table (2) also, no statistically significant difference between both groups regarding onset of leakage, gestational age, gravidity, parity or history of miscarriage.

On other side, Table (3) showed there is a statistically significant difference between both groups regarding AFI, but there are no statistically significant differences between systolic, diastolic blood pressure, respiratory and heart rates and temperature among the studied groups.

There is a statistically significant difference between the two groups regarding vaginal wash urea and creatinine as Table (4) showed.

Table (5) showed the best cutoff of vaginal wash urea in prediction of PROM is $\geq 6.85 \mathrm{mg} / \mathrm{dl}$ with AUC 0.958 , sensitivity $98.2 \%$, specificity 70.2, PPV 76.7, NPV $97.6 \%$ and accuracy $93 \%$ $(p<0.05)$.

On other hand the best cutoff vaginal wash creatinine in prediction of PROM is $\geq 0.465 \mathrm{mg} / \mathrm{dl}$ with AUC 0.992, sensitivity 100, specificity 80.7, PPV 83.8, NPV 100, and accuracy 90.4\% ( $p<0.05)$. Table (6) demonstrated that performance of combined vaginal wash urea and creatinine in both 
groups in prediction of PROM had a sensitivity of 98.3\%, specificity $91.2 \%$, PPV $91.8 \%$, NPV $98.1 \%$ and accuracy $94.7 \%$.

Table (1): Comparison of age and BMI among studied groups.

\begin{tabular}{lcccc}
\hline & PROM & Control & $t$ & $p$ \\
\hline $\begin{array}{l}\text { Age: } \\
\text { Mean } \pm \text { SD }\end{array}$ & $27.44 \pm 6.97$ & $28.65 \pm 7.69$ & -0.881 & 0.380 \\
BMI: & & & & \\
$\quad$ Mean \pm SD & $24.53 \pm 5.56$ & $25.67 \pm 6.12$ & -1.041 & 0.3 \\
\hline
\end{tabular}

Table (2): Comparison of obstetric data among studied groups.

\begin{tabular}{|c|c|c|c|c|}
\hline & PROM & Control & MW & $p$ \\
\hline \multicolumn{5}{|c|}{$\begin{array}{l}\text { Gestational age } \\
\text { (weeks): }\end{array}$} \\
\hline Range & $24-36$ & $24-34$ & $t$ & 0.540 \\
\hline Mean \pm SD & $31.6 \pm 3.67$ & $31.19 \pm 3.34$ & $(0.614)$ & \\
\hline \multicolumn{5}{|l|}{ Gravidity: } \\
\hline Range & $1-6$ & $1-7$ & -0.754 & 0.451 \\
\hline Mean \pm SD & $3.04 \pm 1.8$ & $3.33 \pm 1.8$ & & \\
\hline \multicolumn{5}{|l|}{ Parity: } \\
\hline Range & $0-5$ & $0-5$ & -0.860 & 0.390 \\
\hline Mean \pm SD & $1.82 \pm 1.85$ & $2.12 \pm 1.77$ & & \\
\hline \multicolumn{5}{|l|}{ Abortion: } \\
\hline Range & $0-3$ & $0-3$ & -0.643 & 0.520 \\
\hline Mean \pm SD & $0.47 \pm 1.1$ & $0.46 \pm 0.95$ & & \\
\hline \multicolumn{5}{|c|}{$\begin{array}{l}\text { Onset of leakage } \\
\text { (days): }\end{array}$} \\
\hline Range & $0.04-7$ & $0.04-7$ & -1.044 & 0.296 \\
\hline \multirow[t]{2}{*}{ Mean \pm SD } & $1.14 \pm 1.55$ & $1.67 \pm 1.96$ & & \\
\hline & $\mathrm{N}(\%)$ & $\mathrm{N}(\%)$ & $X^{2}$ & $p$ \\
\hline \multicolumn{5}{|l|}{ History of } \\
\hline \multicolumn{5}{|l|}{ PROM: } \\
\hline Negative & $15(26.3) \%$ & $47(82.5) \%$ & 0.21 & \\
\hline Positive & $42(73.7) \%$ & $10(17.5) \%$ & & \\
\hline
\end{tabular}

$t$ independent sample $t$-test

MW Mann-Whitney test

$p \leq 0.05$ is significant.

Table (3): Comparison of amniotic fluid index and vital signs values among studied groups.

\begin{tabular}{lllll}
\hline & \multicolumn{1}{c}{ PROM } & \multicolumn{1}{c}{ Control } & \multirow{2}{*}{$t$} & $p$ \\
\cline { 2 - 3 } & \multicolumn{1}{c}{ Mean \pm SD } & Mean \pm SD & & \\
\hline $\begin{array}{l}\text { Systolic blood } \\
\text { pressure }\end{array}$ & $103.86 \pm 9.78$ & $104.47 \pm 9.94$ & -0.333 & 0.740 \\
$\begin{array}{l}\text { Diastolic blood } \\
\text { pressure }\end{array}$ & $69.56 \pm 5.85$ & $70.7 \pm 5.86$ & -1.04 & 0.3 \\
$\begin{array}{l}\text { Respiratory rate } \\
\text { Heart rate }\end{array}$ & $15.39 \pm 1.4$ & $15.44 \pm 1.4$ & -0.2 & 0.842 \\
Temperature & $73.04 \pm 3.79$ & $72.98 \pm 3.78$ & 0.074 & 0.941 \\
AFI & $7.02 \pm 1.64$ & $37.4 \pm 0.32$ & 0.087 & 0.930 \\
\hline
\end{tabular}

AFI: Amniotic fluid index.
Table (4): Comparison of urea and creatinine levels $(\mathrm{ml} / \mathrm{dl})$ in vaginal wash fluid among studied groups.

\begin{tabular}{llllll}
\hline & \multicolumn{1}{c}{ PROM } & & Control & & \multirow{2}{*}{$t$} \\
\cline { 2 - 3 } & Mean \pm SD & & Mean \pm SD & & $p$ \\
\hline Urea & $13.45 \pm 3.48$ & & $6.52 \pm 1.89$ & 13.219 & $<0.001 * *$ \\
Creatinine & $1.78 \pm 0.55$ & & $0.36 \pm 0.13$ & MW (-9.099) & $<0.001 * *$ \\
\hline
\end{tabular}

$t$ independent sample $t$-test.

MW Mann-Whitney test.

$p \leq 0.001$ is highly significant.

Table (5): The accuracy of urea and creatinine in vaginal wash fluid in PROM prediction among studied cases.

\begin{tabular}{|c|c|c|c|c|c|c|c|}
\hline & Cutoff & AUC & $\begin{array}{l}\text { Sensi- } \\
\text { tivity }\end{array}$ & $\begin{array}{l}\text { Speci- } \\
\text { ficity }\end{array}$ & PPV & NPV & Accuracy \\
\hline Urea & $\begin{array}{l}6.85 \\
\mathrm{mg} / \mathrm{dl}\end{array}$ & 0.958 & 98.2 & 70.2 & 76.7 & 97.6 & 93 \\
\hline Creatinine & $\begin{array}{l}0.465 \\
\mathrm{mg} / \mathrm{dl}\end{array}$ & 0.994 & 100 & 80.7 & 83.8 & 100 & 90.4 \\
\hline
\end{tabular}

Table (6): Performance of combined vaginal wash urea and creatinine in prediction of PROM among study cases.

\begin{tabular}{lccc}
\hline & PROM & Control & Total \\
\hline Screening test positive & 102 & 10 & 112 \\
Screening test negative & 12 & 104 & 116 \\
\hline Total & 114 & 114 & 228 \\
\hline & & & \\
& & Value & \\
& & 98.3 & \\
\cline { 2 - 3 } & Sensitivity & 91.2 & \\
Specificity & & 91.8 & \\
PPV & & 98.1 & \\
NPV & & 94.7 & \\
Accuracy & &
\end{tabular}

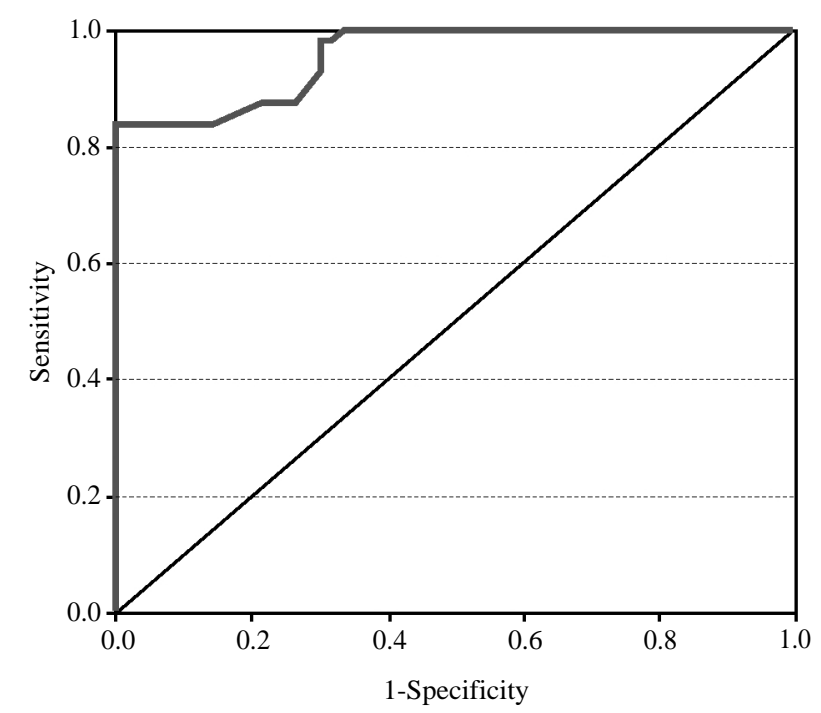

Fig. (1): ROC curve showing performance of vaginal wash urea in prediction of PROM in studied patients. 


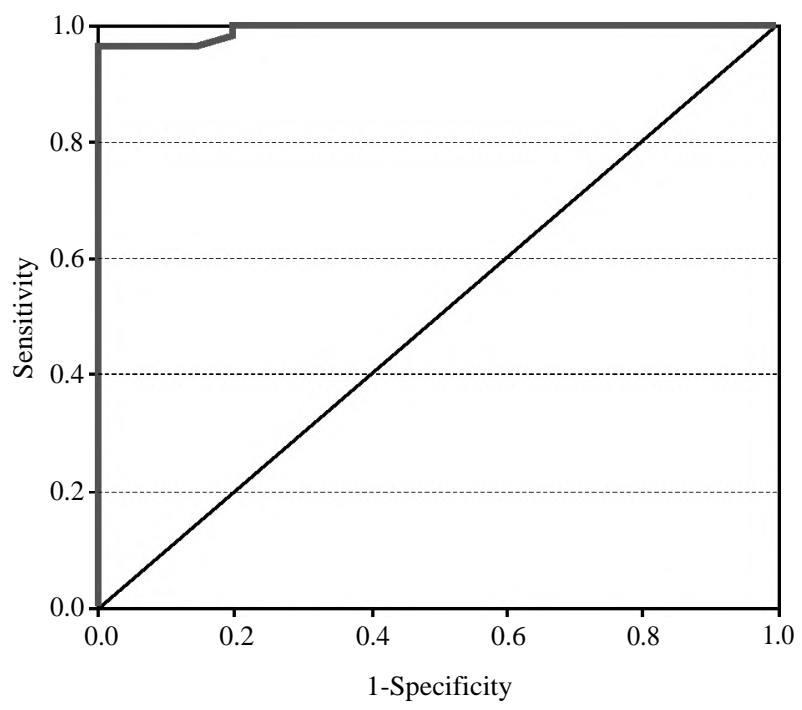

Fig. (2): ROC curve showing performance of vaginal wash creatinine in prediction of PROM in studied patients.

\section{Discussion}

PROM refers to rupture of fetal membrane before the onset of labor. PROM occurs in about $8 \%$ of term pregnancies and about $30 \%$ of preterm pregnancies, with risk of infection and preterm birth [7].

The falsely diagnosed rupture of membranes may lead to improper management such as hospital admission or induction of labor. Therefore, establishment of a crucial diagnosing of rupture of membranes is strongly needed in doubtful cases without deferral [8].

PROM is diagnosed clinically and it is suspected by a typical history of vaginal discharge watery in nature and is confirmed on sterile speculum examination. The conventional gold standard minimally invasive tests for PROM diagnosis based on: inspection of fluid leaking from the cervical os or clear fluid pooling into the posterior vaginal fornix by sterile speculum examination and microscopic ferning or changed color of nitrazine paper to blue denoting alkalinity of the cervico-vaginal discharge [9].

Diagnose of PROM by history has been shown to be reliable only in $10-50 \%$ of patients. However fluid leaking inspection from cervix is the traditional method of sure diagnosis with $15-30 \%$ false negative results [11].

Nitrazine paper test may lead to false negative or positive results due to contaminated samples by semen, blood, alkaline urine, vaginitis or using antibiotics. Fern test also has 5-30\% false positive and $15-30 \%$ false negative results [10].
Accurate diagnosis is achieved by demonstration of specific amniotic fluid markers in vaginal discharge. These tests include detection of afetoprotein, prolactin, di-amine oxidase, human chorionic gonadotropin, insulin like growth factor binding protein-1 (IGFBP-1), and fetal fibronectin. Most of these tests have the advantage of being accurate but expensive and time consuming with variable results [12]. The direction has been on studying urea and creatinine detection in cervicovaginal discharge. These studies declared accuracy of $90-100 \%$ to determine the PROM [13].

Urea and creatinine in the amniotic fluid are produce from fetal urine in second half of pregnancy. Urea plays an important role in the metabolism of nitrogen-containing substances and is the chief nitrogen-containing substance in the urine. Creatinine is a break-down product of creatinine phosphate in muscles and is usually produced at invariant rate and is mainly filtered out through the kidneys [14].

Kafali and Oksuzler [12] presumed that urea and creatinine in vaginal fluid may be helpful in PROM diagnosis because fetal urine is the main source of amniotic fluid in the second half of pregnancy.

This study was conducted to evaluate the diagnostic value of vaginal wash urea and creatinine levels in patients with PROM. The study was carried out at the Department of Obstetrics and Gynecology, Zagazig University Hospitals. A total of 228 pregnant women were included in study, between completed 24 weeks to completed 37 weeks' gestation, divided into two equal groups: 114 pregnant women with PROM and 114 pregnant women with no history of fluid leaking.

The study showed that there is non-significant difference between both groups regarding age, BMI, onset of leakage, gestational age, gravidity, parity, history of miscarriage, blood pressure, respiratory and heart rates and temperature, but there is statistically significant difference between the studied groups regarding AFI.

Kariman et al. [5] evaluated the vaginal fluid urea and creatinine reliability for PROM diagnosis. A total of 179 pregnant women were included in the study. The first group consisted of 126 pregnant women between 14-41 weeks' gestation with history of vaginal fluid leakage. Patients who had visual pooling, positive nitrazine paper and fern test results were considered as confirmed PROM (Group 1). While patients without visual pooling, negative nitrazine paper and fern test results were 
taken as suspected unconfirmed PROM cases (Group 2). The control group consisted of 53 pregnant women with no leaking complaint or complication (Group 3). Age, parity, gravidity and gestational age were compared with analysis of variance between groups.

Our study found a statistically significant difference between the two groups concerning vaginal wash urea. The best cutoff value of vaginal wash urea in prediction of PROM is $\geq 6.85 \mathrm{mg} / \mathrm{dl}$ with AUC of 0.958 , sensitivity of $98.2 \%$, specificity of $70.2 \%$, PPV of $76.7 \%$, NPV of $97.6 \%$ and accuracy of $93 \%$.

Kafali and Oksuzler [12] found that mean vaginal fluid urea levels in definite PROM, suspected PROM and control groups were $34.6 \pm 5.3 \mathrm{mg} / \mathrm{dl}$, $2.4 \pm 5.3 \mathrm{mg} / \mathrm{dl}$ and $1.3 \pm 6.2 \mathrm{mg} / \mathrm{dl}$ respectively, where the difference was statistically significant $(p<0.01)$ with sensitivity, specificity, positive predictive value, and negative predictive value were $100 \%$ for all and cut off value of $12 \mathrm{mg} / \mathrm{dl}$.

Tita and Andrews [15], evaluated vaginal fluid urea concentration and found that the mean vaginal fluid urea levels in confirmed PROM, suspected PROM and control groups were $9.04 \pm 0.57,4 \pm 0.31$ and $3.3 \pm 1.7 \mathrm{mg} / \mathrm{dl}$ respectively, where the difference was statistically significant $(\mathrm{p}<0.05)$. The sensitivity, specificity, and positive and negative predictive value were $100 \%, 76.5 \%, 70.6 \%$ and $96 \%$, respectively and cut off value of $3.5 \mathrm{mg} / \mathrm{dl}$.

Also, David et al. [16] found that mean vaginal fluid urea levels in confirmed PROM and control group were $27.6 \pm 6.2 \mathrm{mg} / \mathrm{dl}$ and $1.1 \pm 2.7 \mathrm{mg} / \mathrm{dl} \mathrm{re}$ spectively, where the difference was statistically significant $(p$-value $<0.05)$ with sensitivity, specificity, positive predictive value, and negative predictive value were $83 \%, 97.3 \%, 96.5 \%$ and $85.6 \%$ respectively and cut off value of $9.6 \mathrm{mg} / \mathrm{dl}$.

Kariman et al. [5] studied the mean concentration of vaginal wash fluid urea in confirmed PROM, suspected PROM and control groups. The mean urea levels in vaginal wash fluid in group 1,2 and 3 were $13.77 \pm 5.41 \mathrm{mg} / \mathrm{dl}, 4.71 \pm 3.64 \mathrm{mg} / \mathrm{dl}$ and $5.13 \pm 5.97 \mathrm{mg} / \mathrm{dl}$ respectively with statistically significant differences $(p<0.001)$. The area under the curve is $84 \%$ for urea. The optimal cut-off value for urea is $6.0 \mathrm{mg} / \mathrm{dl}$ with sensitivity of $90 \%$, specificity of $79 \%$, positive predictive value of $83 \%$, negative predictive value of $87.5 \%$ and accuracy of $85 \%$ were found.

Our study showed that there is a statistically significant difference between the two groups regarding vaginal wash creatinine. The best cutoff value of vaginal wash creatinine in prediction of PROM is $\geq 0.465$ with AUC of 0.992 , sensitivity of $100 \%$, specificity of $80.7 \%$, PPV of $83.8 \%$, NPV of $100 \%$ and accuracy of $90.4 \%$.

Li et al. [17] found that creatinine detection in vaginal wash fluid is easier and less expensive than hCG \& AFP and appears to be more accurate than hCG in diagnosing PROM. The study group involved 54 women in their 3rd trimester of pregnancy with confirmed PROM and the control group involved 34 pregnant women without PROM. The vagina was washed by $3 \mathrm{ml}$ of saline solution injected by syringe, and the collected fluid was taken for creatinine quantitative assay. The results statistics were with a significant level of $p<0.05$.

These results cope with the results of Harita et al. [18] in evaluation of creatinine concentration in vaginal wash fluid for PROM detection, where sensitivity, specificity, negative predictive value, and positive predictive value were $94 \%, 90 \%$, $88.6 \%$ and $100 \%$ respectively and cut off value of $0.55 \mathrm{mg} / \mathrm{dl}$.

Gurbuz et al. [19] showed that creatinine detection in vaginal wash fluid is a useful marker in suspected cases of PROM. In these cases, new methods such as fetal fibronectin, $\beta$-hCG and AFP were investigated. However, because of values overlap in patients with ruptured and intact membranes, they have low specificity. The creatinine assay is excelled in being fast and cheap with high accuracy to establish diagnosis. It is likely to be a ideal test for PROM diagnosis by evaluation of vaginal fluid creatinine concentration with sensitivity, specificity, positive predictive value, and negative predictive value were $100 \%$ for all.

Kafali and Oksuzler [12] found that mean creatinine levels of vaginal wash fluid of definite PROM, suspected PROM and control groups were $1.5 \pm 0.3 \mathrm{mg} / \mathrm{dl}, 0.34 \pm 0.22 \mathrm{mg} / \mathrm{dl}$ and $0.28 \pm 0.23 \mathrm{mg} / \mathrm{dl}$ respectively, where the differences were statistically significant ( $p$-value $<0.01$ ) with sensitivity, specificity, positive predictive value, and negative predictive value were $100 \%$ for all and cut off value of $0.6 \mathrm{mg} / \mathrm{dl}$.

Also, Tita and Andrews [15] found that the mean creatinine level of vaginal wash fluid of confirmed PROM, suspected PROM and control groups were $0.82 \pm 0.05,0.55 \pm 0.04$ and $0.07 \pm 0.02 \mathrm{mg} / \mathrm{dl}$ respectively, where the differences were statistically significant $(p<0.05)$. The sensitivity, specificity and positive and negative predictive values were 
$90.2 \%, 91.2 \%, 83.6 \%$ and $90 \%$ respectively with a cut off value of $0.75 \mathrm{mg} / \mathrm{dl}$.

Kariman et al. [5] demonstrated that creatinine has the higher diagnostic power with the mean creatinine level in vaginal wash fluid among confirmed PROM, suspected PROM and control groups were $1.58 \pm 1.01 \mathrm{mg} / \mathrm{dl}, 0.36 \pm 0.23 \mathrm{mg} / \mathrm{dl}$ and $0.22 \pm$ $0.10 \mathrm{mg} / \mathrm{dl}$ respectively. The differences between groups were statistically significant $(p<0.001)$. The area under the curve for creatinine is $99.99 \%$. From the ROC curve, $0.45 \mathrm{mg} / \mathrm{dl}$ was set as a cut-off value for creatinine. The sensitivity, specificity, positive predictive value, negative predictive value and accuracy were $100 \%$ for all.

A study was carried out by Mohamed and Mostafa [20] for detecting PROM by evaluation of vaginal urea and creatinine concentration. The sensitivity, specificity, positive predictivity and negative predictivity were $100 \%$ for all with cutoff values of $13.2 \mathrm{mg} / \mathrm{dl}$ and $0.31 \mathrm{mg} / \mathrm{dl}$ respectively.

In our study, combined use of vaginal wash urea and creatinine in prediction of PROM had sensitivity of $98.3 \%$, specificity of $91.2 \%$, PPV of $91.8 \%$, NPV of $98.1 \%$, accuracy of $94.7 \%$.

Kafali and Oksuzler [12] have found that determination of vaginal wash fluid urea and creatinine for the diagnosis of PROM was a simple, reliable, inexpensive and rapid test. Creatinine values in the amniotic fluid stand for fetal maturity. A creatinine concentration of $\geq 1.75 \mathrm{mg} / \mathrm{dl}$ correlates significantly with a gestational age of 37 weeks or more, which confirmed renal maturation.

Our study showed that urea and creatinine assays are cheap and fast methods with high sensitivity and specificity to establish accurate diagnosis. It is possible to be a gold standard test for PROM as it is cheaper, faster with higher sensitivity and specificity than $\alpha-\mathrm{FP}, \beta-\mathrm{HCG}$ and fetal fibronectin.

Oliveira et al. [21] found a significant correlation between gestational age and amniotic fluid creatinine $(r>0.85, p<0.01)$. Meanwhile, Creatinine concentrations in amniotic fluid increased gradually between 20-32 weeks of gestation and more rapidly thereafter, when they were two to four times higher than in maternal serum.

Osman and Elghazaly [22] evaluated the accuracy of urea and creatinine in vaginal wash fluid for diagnosis of PROM and found that they are accurate, inexpensive and simple tests for diagnosis of PROM.
Gezer et al. [23] concluded that measurement of urea and creatinine levels in vaginal wash fluid in cases of PPROM is a reliable and rapid test for diagnosis and also for delivery interval prediction after PPROM.

Conclusion: This study concluded that urea and creatinine assay is cheaper, faster and more valid (has higher sensitivity and specificity) than other vaginal fluid markers as $\alpha$-fetoprotein, human chorionic gonadotropin and fetal fibronectin to establish accurate diagnosis of PROM. In the present series, the simplicity and the availability of this test make it easier in clinical practice. So, vaginal fluid creatinine and urea are possible candidates to become an ideal test for diagnosis of PROM. The study also recommended application of these new tests as a routine investigation in diagnosis of PROM in a large scale of population.

Ethics approval and consent to participate: Institutional review board's approval of Zagazig University was obtained and written informed consent was taken from all patients.

Consent for publication: Consent was obtained from all patients regarding participation and publication of the study results with all respect to confidentiality. All authors accept the publication.

Availability of data and material: Data was recruited from cases attending obstetric outpatient clinics of Zagazig University Hospitals.

Competing interests: The authors have no competing interests relevant to this article.

Funding: The authors state that this work has not received any funding.

Authors' contributions: All authors participated in sampling, data collection, intervention and statistical analysis. All authors have read and approved the manuscript.

\section{References}

1- CUNNINGHAM G., LEVENO K., BLOOM S., et al.: William's Obstetrics, 24 th Edition. New York: McGrawHill Education, 2014.

2- BORNSTEIN J., GEVA A., SOLT I., et al.: Nonintrusive diagnosis of premature ruptured amniotic membranes using a novel polymer. Am. J. Perinatol., 23: 351-4, 2006.

3- PALACIO M., KUHNERT M., BERGER R., et al.: Metaanalysis of studies on biochemical marker tests for the diagnosis of premature rupture of membranes: Comparison of performance indices. BMC Pregnancy and Childbirth, 14: 183, 2014.

4- NI C.Y., JIA W.X., YI W.M., et al.: Practicability of using vaginal fluid markers in detecting premature rupture of membranes. Ann. Clin. Biochem., 40: 542-5, 2003. 
5- KARIMAN N., AFRAKHTE M., HEDAYATI M., et al.: Diagnosis of premature rupture of membranes by assessment of urea and creatinine in vaginal washing fluid. Iran J. Reprod Med., 11 (2): 93-100, 2013.

6- DEAN F.: Statistical methods in scientific researches. European Journal of Scientific Research, 14 (3), 2006.

7- PARK J.S., LEE S.E. and NORWITZ E.R.: Non-invasive testing for rupture of the fetal membranes. Touch Briefings: US Obstetrics and Gynecology, Issue 1: 13-6, 2007.

8- WATERS T.P. and MERCER B.M.: The management of preterm premature rupture of the membranes near the limit of fetal viability. Am. J. Obstet. Gynecol., 201 (3): 230-40, 2009.

9- LIU J., FENG Z.C. and WU J.: The Incidence Rate of Premature Rupture of Membranes and its Influence on Fetal-neonatal Health: A Report from Mainland China. J. Trop. Pediatr., 56: 36-42, 2010.

10- KONIMCKX P.P., TRAPPENIERS H. and ASSCHE F.A.: Prolactin concentration in vaginal fluid: A new method for diagnosing ruptured membranes. British J. Obstet. Gynecol., 88: 607, 2011.

11- SUCAK A., MOROY P. and CAKMAKL P.: Insulin-like growth factor binding protein-1: A rapid detection of amniotic fluid leakage after amniocentesis. Turk J. Med., 35: 157-161, 2005.

12- KAFALI H. and OKSUZLER C.: Vaginal fluid urea and creatinine in diagnosis of premature rupture of membranes. Arch. Gynecol. Obstet., 275: 157-160, 2007.

13- CAMERON E.: Diagnosis of premature rupture of membranes: Inspiration from the past and insights for the Future. J. Obstet. Gynecol. Can, 32: 561-569, 2010.

14- NICOLAOU, KYRIACOS C. and TAMSYN M.: Molecules That Changed the World. Wiley-VCH, 2008.
15- TITA A.T. and ANDREWS W.W.: Diagnosis and management of clinical chorioamnionitis, 2010.

16- DAVIDSON J.N.: Detection of premature rupture of the membranes. Clin. Obstet. Gynecol., 34: 715-22, 2011.

17- LI H.Y. and CHANG T.S.: Vaginal fluid creatinine, human chorionic gonadotropin and alpha-fetoprotein levels for detecting premature rupture of membranes. Zhonghua Yi Xue Za Zhi (Taipei) 63: 686-690, 2000.

18-HARITA N., HAYASHI T., SATO K., et al.: Lower Serum Creatinine is a New Risk Factor of Type 2 Diabetes: The Kansai Healthcare Study. Diabetes Care, 32: 424, 2010.

19- GURBUZ A., KARATEKE A. and KABACA C.: Vaginal fluid creatinine in premature rupture of membranes. Int. J. Gynecol. Obstet., 86: 270-271, 2004.

20 - MOHAMED A. and MOSTAFA W.: The Value of Measurement of Vaginal Fluid Urea, Creatinine and Beta HCG in the Diagnosis of Premature Rupture of Membranes. KAJOG, 2: 41-47, 2011.

21- OLIVEIRA F.R., BARROS E.G. and MAGALHES J.A.: Biochemical profile of amniotic fluid for the assessment of fetal and renal development. Braz J. Med. Biol. Res., 35: 215-222, 2002.

22- OSMAN O.M. and ELGHAZALY M.: Can vaginal washing fluid urea, creatinine and qualitative $\beta$-hCG diagnose suspected premature rupture of membranes? Open Journal of Obstetrics and Gynecology, 4: 967-972, 2014.

23- GEZER C., EKIN A., GOLBASI C., et al.: Use of urea and creatinine levels in vaginal fluid for the diagnosis of preterm premature rupture of membranes and delivery interval after membrane rupture. The Journal of MaternalFetal and Neonatal Medicine, 4: 967-972, 2016. 


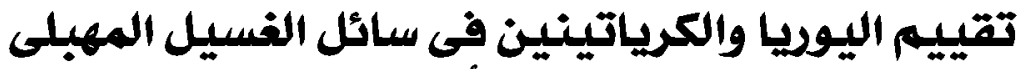

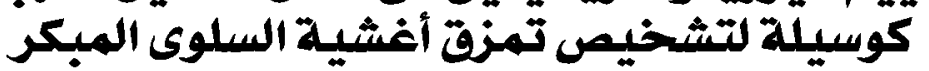

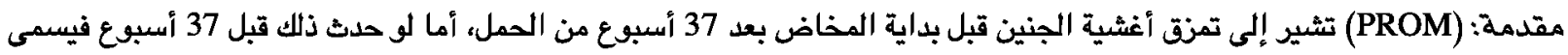

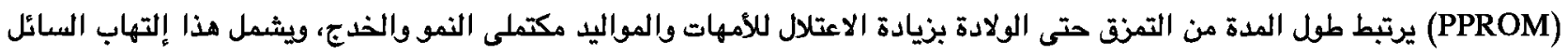

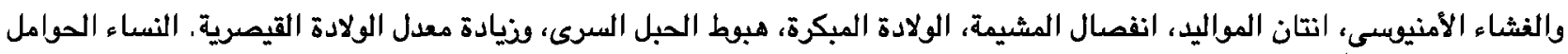

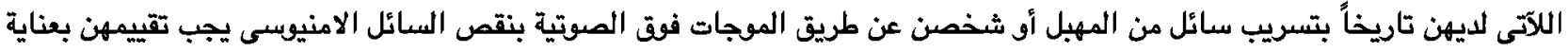

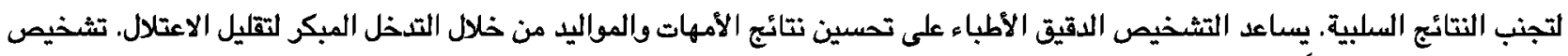

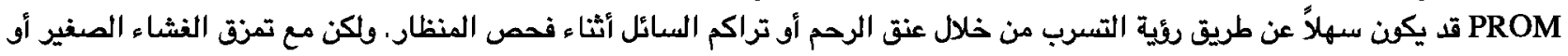

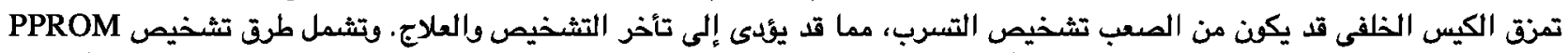

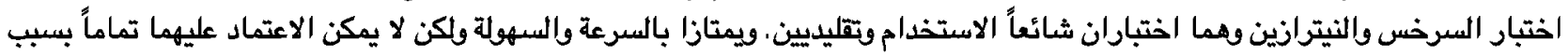

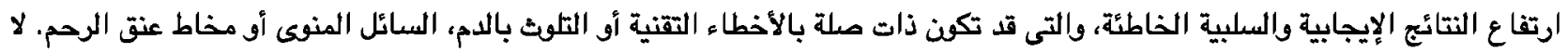

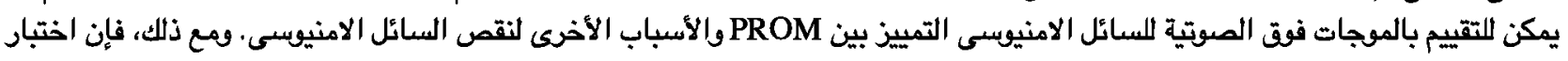

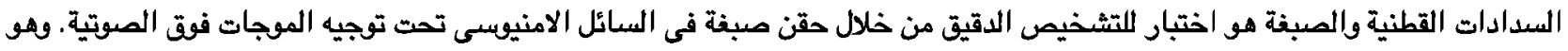

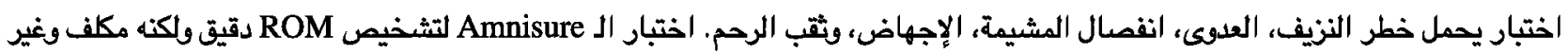

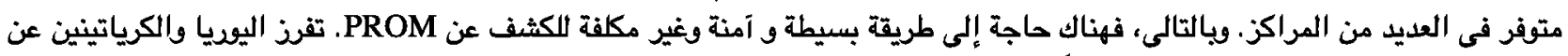

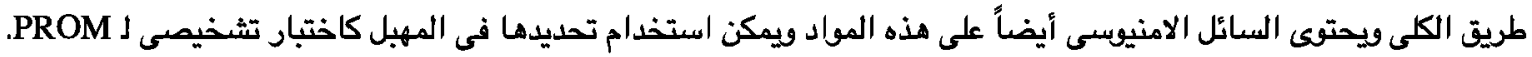
الهدف من الدراسة: أجريت هذه الدراسة لبحث القيمة الشتخيصية لمستويات اليويا والكرياتينين فى سائل الغسيل المهبلى فى المرضى لونى الذين يعانوف من اشتباه بـ البراستجريت هذه

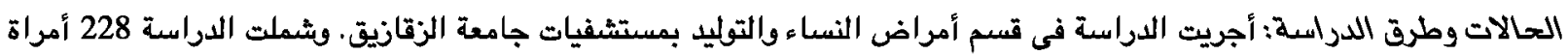

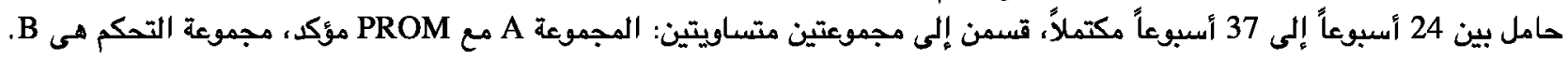

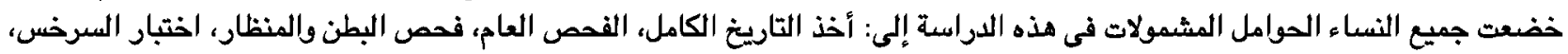

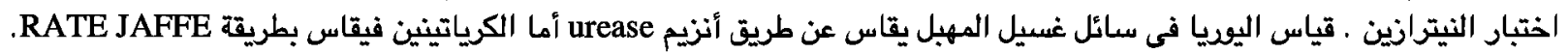

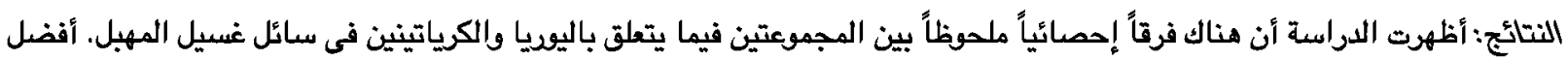

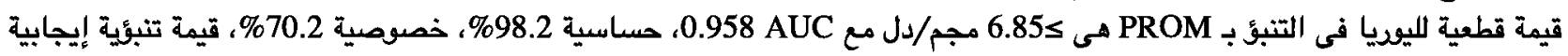

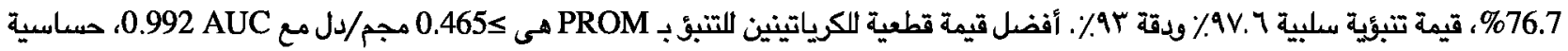

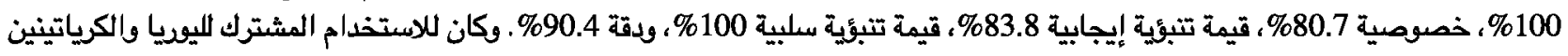

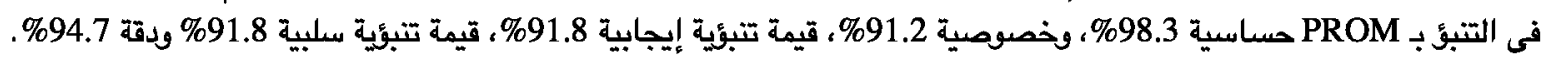

الاستتاج: خلمت هذه الدراسة إلى أن فحص اليويا والكرياتينين فى السائل المهبلى أرخص وأسرع وأكثر دقة، وهو مرشح محتمل لكونه اختباراً قياسياً ذهبياً لتشخيص PROM. 